\title{
Addressing shame: what role does shame play in the formation of a modern medical professional identity?
}

\author{
Sandy Miles (10)
}

BJPsych Bulletin (2020) 44, 1-5, doi:10.1192/bjb.2019.49

St Andrew's Surgery, Eastleigh, UK Correspondence to Dr Sandy Miles (Sandy.miles2@nhs.net)

First received 13 Mar 2019, final revision 11 Jun 2019, accepted 18 Jun 2019

(c) The Author 2019. This is an Open Access article, distributed under the terms of the Creative Commons Attribution licence (http:// creativecommons.org/licenses/by/ 4.0/), which permits unrestricted reuse, distribution, and reproduction in any medium, provided the original work is properly cited.

\begin{abstract}
Summary Shame is a highly prevalent, though rarely discussed, emotion experienced by trainee doctors. Seeking to avoid the pain of shame can cause significant distress and maladaptive behaviours. However, it plays a key role in helping doctors identify their moral values which, in turn, form the basis of their medical professional identity. This article uses personal doctors' narratives together with sources from sociology, psychology and medical education to address shame as experienced by medical trainees - its causes, effects and remedies that doctors and medical educators can use to neutralise its malign effects.
\end{abstract}

Declaration of interest None.

Keywords Education and training; shame; identity.
Shame is a powerful, primitive emotion that plays an important role in identity formation ${ }^{1}$ (p. 568). Doctors feel shame when they fail to live up to the values that they feel are essential to maintaining their professional identity. It is often a quiet emotion, resulting in withdrawal, so can be easily missed by colleagues and educators. It is such a painful emotion that most strive to avoid it making it potentially destructive. However, feeling a sense of shame can drive the prosocial behaviour of helping others and increase doctors' awareness of their important core values. These are vital in forming a well-rounded medical professional identity. Shame, its causes and effects, needs to be understood by trainee doctors and those involved in training them.

\section{Shame and identity}

Shame is linked to fear of a loss of, or soiling of, identity. The expression of shame is to cover the self, blush and withdraw. To make oneself small and unobtrusive or indeed diminish others, are hallmarks of shame. Guilt, embarrassment and shame are subject to differing definitions, often used interchangeably in dialogue, but are distinct concepts. Embarrassment is a brief and relatively painless reaction to becoming aware of breaking a social norm, such as using the wrong form of speech or dress in the presence of others. Like shame, it is characterised by blushing, but distinctly it often gives rise to laughter about the occasion later. ${ }^{2}$ Shame and guilt, however, are longer lasting and more deeply felt emotions. Helen Lewis, ${ }^{3}$ who studied the shame felt by those undergoing psychotherapy, clarified the difference between shame and guilt:
'Shame is about self. We say I am ashamed of myself. I am guilty of something. Guilt is out there in the real world, something you did or something you shouldn't have thought. Shame is only about the self.' $\quad$ Lewis $^{3}$ (p. 32)

Guilt is linked to a transgression of norms and rules whereas shame is triggered by falling short of a value deemed by an individual to be central to their concept of self. Accordingly, guilt plays little significant role in the formation of identity, but shame does. Shame is therefore 'an emotional reaction to failing to live up to one's image of oneself ${ }^{4}$ (p. 168). Part of the difficulty and pain caused by shame is that the very word repels people. The study and discussion of shame is thus hampered in medicine by the visceral negative response generated by its association with the pain of disgrace and mortification. As Lazare says it is shameful and humiliating to admit that one has been shamed and humiliated $^{5}$ (p. 1658).

Trainee doctors 'need to develop a professional identity - ways of being and relating in professional contexts' 6 (p. 641). Social constructionist theory states that identities are not innate and defined biologically, but are formed by individuals learning certain core values from the social group to which they belong and adopting them into their idea of self. ${ }^{7}$ One of the subliminal messages communicated to trainees by established doctors is the need to supress emotions to be competent, delivering necessary but occasionally painful or unpleasant treatment to patients. Elton ${ }^{8}$ highlights the distinction between this practical, conscious and temporary deferment of emotion and the more pernicious defensive strategy of repression where 'difficult emotions are pushed out of the conscious mind entirely' (p. 58). Medical educator and general practitioner Roger 
Neighbour also recognises the presence of this regulatory 'Crichton's switch'. He named this after the author Michael Crichton, who described his experience of detachment as 'a click, a shutting off' when dissecting the head of a corpse in his anatomy training at Harvard in the 1960s:

I later learned that this shutting off click was essential to becoming a doctor. You could not function if you were overwhelmed by what was happening...I had to find a way to guard against how I felt.

And still later I learned that the best doctors found a middle position where they were neither overwhelmed by their feelings nor estranged from them, that was the most difficult position of all, and the precise balance - neither too detached nor too caring - was something few learned.' Neighbour ${ }^{9}$ (p. 213)

Crichton's views are supported by recent research surveying 7000 physicians, which found that those who are best able to regulate their emotions rather than detach themselves from any feelings, are least prone to emotional exhaustion and low self-accomplishment. ${ }^{10}$ Feelings of shame can cause trainees to emotionally and physically withdraw from patients. There is a well-documented reduction in empathy among medical students from the start of the patient facing, clinical part of their training. ${ }^{11}$ Theories abound as to the cause of this, from the emotionally overwhelming clinical environment ${ }^{12}$ to seeing role models denigrate patients. ${ }^{13}$ I believe the shame of witnessing patients in vulnerable states of illness is a large contributory factor. Lack of acknowledgment of this shame drives trainees to view this emotional detachment as a key professional skill. Being party to unethical care and the humiliation of patients and peers also drives trainees to emotionally withdraw, splitting their personal and professional identities as a protection mechanism against shame. So, an essential part of a medical professional identity is learning to regulate, but not be estranged from, emotions including shame. This is not adequately addressed in medical training.

\section{Shame in medical training}

Medical training does not provide doctors with sufficient guidance on how to deal emotionally with the inevitable, unpredictable crises that they will encounter at work. Despite receiving little attention in medical education literature there is a current boom of personal narratives by doctors describing the role of shame and other emotions in their medical experiences. ${ }^{14}$ An exposé, by occupational psychologist Caroline Elton, ${ }^{8}$ of the emotional difficulties experienced by trainee doctors, challenges the myth that doctors' professionalism relies on them not experiencing feelings. She describes medicine's 'conspiracy of silence' (p. xvi), with doctors unable to express their doubts and fears about the challenges of medical practice to colleagues as they are made to feel inadequate. She argues that this silence and lack of acknowledgment that doctors have ordinary human desires and feelings leads to deep distress, premature departure from the profession and, at its worst, death by suicide. The emotion that is the least discussed, and most feared, is that of shame. The medical profession's outrage at the recent public shaming of Dr Bawa-Garba ${ }^{15}$ for a clinical error, speaks to the fears of many doctors that they too are at risk of similar, mortifying exposure as a result of their work.
Batchelor $^{16}$ opines that students' ontological voice is silenced in higher education as the emphasis is on the strong, positive outcomes of doing and knowing rather than acknowledging vulnerability and fallibility. This is particularly evident in medical training, despite the inherent lack of certainty in clinical practice. The lack of attention to these areas mean trainees not only experience shame when they face moral challenges, but also fail to recognise or admit it. It is repressed, like other emotions, leading to negative consequences for themselves and their patients. Bochner ${ }^{17}$ argues forcefully that the more physicians know about their own emotions and subjectivity in the context of their doctoring, the better prepared they are to understand their patients and treat them ethically and effectively (p. 163). Paraphrasing Montaigne, to help trainees create authentic identities, they need to be encouraged to examine not only 'What do I know?' but more importantly 'Who am I? ${ }^{18}$

\section{Causes of shame in medicine}

Doctors are exposed to shame for many reasons. This article examines the shame caused by failing to meet organisational targets, committing clinical errors, not conforming to the norms of an idealised doctor and becoming ill.

The growing surveillance and regulation of trainees and the lengthening lists of essential competences that they must demonstrate, increases their fear of public shaming and the loss of their professional identity. Having to compromise their patients' care to meet externally imposed targets and working in systems where patients are dehumanised and treated as 'outcomes' or 'data sets' is inherently shaming. They are forced to adhere to guidelines and priorities that, they may feel, do not bring maximum benefit for the patient that they are treating. Psychologist Erik Erikson, ${ }^{19}$ writing about the psychosocial development of young children, noticed that if they were overly controlled and given insufficient opportunity to assert themselves, they more readily felt shame and doubted their abilities. Junior doctors are finding that increases in managerial oversight of clinical practice, tighter regulation by the General Medical Council (GMC) and financial pressures on National Health Service budgets are narrowing the parameters within which they can practise, reducing their autonomy and making them more prone to shame. They experience a shame-inducing dissonance, as they retain individual professional responsibility for their patients but work in increasingly complex systems over which they have diminishing control.

Doctors feel that they need to perform faultlessly despite creaking systems of care. This becomes their internal benchmark against which they measure themselves. This perfectionism and fear of being exposed is a fertile breeding ground for shame. It has not yet been accepted in medical hierarchies that 'errors are evidence of system flaws not character flaws ${ }^{20}$ (p. 1857).

Forming a medical professional identity can be a shamefully deindividuating process if the educational emphasis is placed on conforming to group values and diversity is not celebrated. Frost and Regehr ${ }^{21}$ argue that competence based medical training promotes standardisation and the idea that there is a 'single way to be a competent 
professional physician' (p. 1570). This approach fails to celebrate students' individuality and recognise that more heterogenous forms of medical identity could benefit doctors and patients. Unalterable characteristics, such as ethnicity and sexual orientation, may not conform to these norms and this creates the potential for chronic shame and an inability for these doctors to fit in. Adopting the social identity of doctors involves deindividualization and conformity to the group rules, resulting in trainees splitting from their own personal identities and exposing themselves to the anxiety of being seen to be 'other'. ${ }^{22}$

Doctors are as prone to illness as anyone, but UK doctors understand that to be sick is shameful. ${ }^{23}$ This shame can derive from a sense of weakness and vulnerability on the part of the doctor, crossing the implicit divide from their colleagues and become something 'other'. This speaks to the unwritten code that doctors are infallible, even to their own illnesses. Sick doctors complain that colleagues seem unable to see their vulnerability and treat them as they would other patients. ${ }^{24}$ However, being a doctor with an illness and becoming a patient does not have to be shameful. In shamanism and ancient Greece, healers were expected to undergo pain and illness as part of their training, with the insights gained used to improve their ability to help others. ${ }^{25}$ The 'wounded healer' archetype can also be interpreted as a defence used by doctors against addressing their own feelings of inadequacy and shame. ${ }^{26}$ Compulsively caring for others and even entering into a 'malignant' symbiosis ${ }^{26}$ (p. 67) with patients means the doctor's emotional needs can only be met by being needed by the helpless. Patients, in turn, are required to enact their doctor's inexpressible feelings and difficulties. The healer is thus wounded by an inability to address their shame, and so imposes ongoing vulnerability on their patients.

\section{Effects of shame in medicine}

In 'Daring Greatly', ${ }^{27}$ Brené Brown claims all reactions to shame result from a fear of disconnection from others. Shame, she says, potentially causes one or several of the triad: moving away (physically withdrawing, silencing the self, keeping secrets), moving toward (seeking to appease and please others) and moving against (seeking to gain power by aggression or shaming others) (p. 77). The unacknowledged shame developed by trainees during their medical identity formation can result in them becoming depressed, addicted to alcohol and drugs, self-harming and leaving medicine. ${ }^{8,28}$ It also causes withdrawal from colleagues and patients, dishonesty, narcissism, unthinking compliance and humiliation of patients. ${ }^{5,29,30}$ A hefty toll.

Notionally, the threat of public shame should cause doctors to behave impeccably at all times. Many researchers claim that shame has a positive role to play in social regulation as it inhibits antisocial behaviour. ${ }^{31-33}$ Psychologists Trower and Gilbert, ${ }^{34}$ however, warn that fear of shame among members of a social group who feel subject to critical scrutiny results in social anxiety, destructive conformity and unthinking deference. Competent doctors can therefore develop pathological anxiety. This, in turn, can result in them concealing medical errors and emotionally withdrawing from patients - the potential complainants.
The GMC has the power to remove doctors from their register, to erase their professional identity. The fear of complaints leading to their involvement, and the stress of following their disciplinary processes if investigated, can cause mental illness among doctors. ${ }^{28}$ Richard Jones, Clinical Director of the NHS Practitioner Health Programme, treating doctors with addiction and mental illness, says that the fear of public shame can even trump the fear of causing patient harm (R. Jones, personal communication, 2018), so there is a reluctance to report errors and learn from them, threatening patient safety. Contrary to the beliefs of many trainees regarding the disciplinary consequences of committing an error, only $20 \%$ of the 119 doctors suspended or erased from the UK medical register in 2014 were sanctioned for (usually multiple) clinical errors, according to GMC research. ${ }^{35}$ More than $50 \%$ of erasures were for dishonesty, mostly related to fraudulent details on application forms and prescriptions. $12 \%$ of cases, however, related to falsifying medical records. For this group, the shame of having their imperfect patient care revealed may have caused them to, retrospectively and dishonestly, alter the patients notes.

The shame of not fitting into the explicit norms of a medical professional identity can also cause problems such as addiction. Jones (R. Jones, personal communication, 2018) noticed that a small group of homosexual doctors went to great lengths to disguise or diminish the expression of their sexuality with their peers at medical school. They masked it with excessive emphasis on technical knowledge and competence. When an error occurred, however, as it inevitably did, their façade of technical infallibility fell down. He understood that their subsequent addiction was a strategy to cope with the shame of revealing their true identity.

A need for appeasement to avoid shame can generate an 'unthinking compliance ${ }^{, 36}$ (p. 1225). This could be a positive outcome when training doctors toward a standardised way of thinking and problem solving. However, the danger is that medical professionals become morally neutral, unquestioning automatons, at the mercy of organisational edicts, and fail to advocate for the needs of their patients.

With all these negative effects it is easy to agree with Tangney when she refers to shame as the "ugly emotion, ${ }^{37}$ (p. 601). However, its significance in identity formation suggests it also has a positive, necessary and moral role to play. As well as causing pain, shame has the potential to motivate people to do good. Through empirical experiments, De Hooge et $a l^{34}$ demonstrated that individuals who experienced or imagined shame were then more likely to act beneficently toward others. Experiencing the pain of shame, in this setting, drove moral behaviour. They proposed that in this case their desire for appeasement drove prosocial behaviour and shame could therefore 'act as a commitment device' (p. 941) to altruism, which is vital in medical professionals.

Shame also has an essential role of making us aware of what we hold dear, what our values are and what is essential to our identity. Analysing Tomkins work on affect in babies, Probyn $^{33}$ unveiled his statement that shame 'operates only after interest or engagement has been activated ${ }^{38}$ (p. 5). Shame is a reminder of 'promises that we keep to ourselves' and 'deep worries and concerns ${ }^{33}$ (p. xi), of which we may have been unaware. Probyn's analysis is that shame makes us feel uncomfortable but nevertheless this can be 
'productive' (p. 15), with greater self-awareness and highlighting opportunities for reforming the self, if needed. In the identity formation of young doctors, this could lead to their experiences of shame showing them the need to stand up for what they feel is morally right.

\section{Addressing shame in medicine}

Brené Brown ${ }^{27}$ explains that it is impossible to avoid shame as it forms an integral part of the human experience. She promotes the benefit of individuals retaining their vulnerability to feeling shame. She claims, however, that it is possible to experience it without sacrificing values and identity. She calls this ability 'shame resilience' (p. 74) and explains that the antidote to shame is self-compassion as well as empathy from others.

Medical trainees' reflective writing, mandated by the GMC to promote the development of professionalism, is not an effective tool for neutralising the pain of shame as studies show that shame is 'difficult to metabolise and address without help ${ }^{39}$ (p. 1023). This points to the need to create a culture where the topic of shame can be discussed openly, ideally with a trusted peer or mentor. An important caveat to this suggestion is to remain aware of the need to respect trainees' privacy in processing their experiences to prevent provoking additional shame, as cautioned by Schneider. ${ }^{40}$ Thus, making face-to-face discussions mandatory may defeat the objective of neutralising shame. Encouraging the expression of vulnerability is key to addressing shame and Zigmond implores medical teachers to share the difficulties they encounter in their practice with their learners to enable them to discuss their own fears and challenges ${ }^{26}$ (p. 70).

\section{Conclusion}

Trainees who feel shame, or fear it, may withdraw by becoming quiet, reducing their attendance at teaching and avoiding questioning or challenging teachers. They may exhibit anger, narcissistic behaviour and humiliate others. They may become mentally ill and self-harm. Helping doctors to recognise and then address shame in themselves and their peers is thus vital for their well-being and patient safety. Understanding that shame can be experienced as discomfort that highlights something of interest to the self can guide trainees to become aware of their core values and use these as opportunities for self-development. Despite the repellent nature of the word, we really do need to talk about shame and its important role in forming a modern medical professional identity.

\section{About the author}

Dr Sandy Miles is a GP and Medical Educator at St Andrew's Surgery, Eastleigh, UK.

\section{References}

1 Kaufman G. The meaning of shame: toward a self-affirming identity. J Couns Psychol 1974; 21(6): 568
2 Tangney J, Miller R, Flicker L, Barlow D. Are shame, guilt and embarrassment distinct emotions? J Pers Soc Psychol 1996; 70(6): 1256-69.

3 Lewis HB. Shame and Guilt in Neurosis. International Universities Press, 1974

4 Lazare A. On Apology. Oxford University Press, 2007

5 Lazare A. Shame and humiliation in the medical encounter. Arch Intern Med 1987; 147(9): 1653-8.

6 Goldie J. The formation of professional identity in medical students: considerations for educators. Med Teach 2012; 34(9): 641.

7 Tajfel $\mathrm{H}$, Turner J. The social identity theory of intergroup behaviour. In Psychology of Intergroup Relations (eds S Worchel, WG Austin): 7-24. Nelson, 1986.

8 Elton C. Also Human: The Inner Lives of Doctors. Heinemann, 2018.

9 Neighbour R. The Inner Physician: Why and How to Practise 'Big Picture Medicine'. Routledge, 2016.

10 Gleichgerrcht E, Decety J. Empathy in clinical practice: how individual dispositions, gender and experience moderate empathic concern, burnout and emotional distress in physicians. PLoS ONE 2013; 8(4): e61526.

11 Hojat M, Mangione S, Nasca T, Rattner S, Erdman J, Gonella J, et al. Empathy in clinical practice: how individual dispositions, gender and experience moderate empathic concern, burnout and emotional distress in physicians. Med Educ 2004; 38(9): 934-41.

12 Chen D, Lew R, Hershman W, Orlander J. A cross-sectional measurement of medical student empathy. J Gen Intern Med 2007; 22(10): 1434-8.

13 Newton B, Barber L, Clandy J, Cleveland E, O'Sullivan P. Is there hardening of the heart during medical school? Acad Med 2008; 83(3): 244-9.

14 Lyons B, Gibson M, Dolezal L. Stories of shame. Lancet 2018; 391 (10130): 1568-9.

15 Torjesen I. Paediatricians condemn treatment of Bawa-Garba. BMJ 2018; 360: k1255.

16 Batchelor D. Vulnerable voices: an examination of the concept of vulnerability in relation to student voice. Educ Philos Theory 2006; 38(6): 787-800.

17 Bochner A. Vulnerable medicine. J Appl Commun Res 2009; 37(2): 159-66.

18 Montaigne M. Essais, tome I, éd. Maurice Rat. Éd. Garnier Frères, 1962

19 Erikson E. Psychological Issues: Identity and the Life Cycle. International Universities Press, 1959.

20 Leape L. Error in medicine. JAMA 1994; 272(23): 1851-7.

21 Frost H, Regehr G. I am a doctor. Acad Med 2013; 88(10): 1570-7.

22 Beagan B. Neutralizing differences: producing neutral doctors for (almost) neutral patients. Soc Sci Med 2000; 51(8): 1253-65.

23 Henderson M, Brooks S, del Busso L, Chalder T, Harvey S, Hotopf M. Shame! Self-stigmatisation as an obstacle to sick doctors returning to work: a qualitative study. BMJ Open 2012; 2: e001776.

24 British Medical Association. Disability Equality Within Healthcare: The Role of Healthcare Professionals. British Medical Association, 2007 (http://www.hscbusiness.hscni.net/pdf/BMA-_Disability_equality_ healthcare_June_2007_pdf.pdf).

25 Kirmayer L. Asklepian dreams: the ethos of the wounded-healer in the clinical encounter. Transcult Psychiatry 2003; 40(2): 248-77.

26 Zigmond D. Physician heal thyself: the paradox of the wounded healer. Br J Holistic Med 1984; 1: 63-71.

27 Brown B. Daring Greatly: How the Courage to be Vulnerable Transforms the Way We Live, Love, Parent, and Lead. Gotham Books, 2012.

28 Gerada C. Doctors, suicide and mental illness. BJPsych Bull 2018; 42(4): 165-8.

29 Lyons B, Dolezal L. Shame, stigma and medicine. Med Humanit 2017; 43 (4): 208-10.

30 Bowman D. Vulnerability, survival and shame in Nina Raine's Tiger Country. Med Humanit 2017; 43(4): 264-8. 
31 Probyn E. Blush: Faces of Shame. University of New South Wales Press, 2005.

32 de Hooge I, Bruegelman S, Zeelenburg M. Not so ugly after all; When shame acts as a commitment device. J Pers Soc Psychol 2008; 95(4): $933-43$.

33 Fessler D. Shame in two cultures: implications for evolutionary approaches. J Cogn Cult 2004; 4(2): 207-62.

34 Trower P, Gilbert P. New theoretical conceptions of social anxiety and social phobia. Clin Psychol Rev 1989; 9(1): 19-35.

35 DJS Research. Analysis of cases resulting in doctors being suspended or erased from the medical register. General Medical Council, 2015 (www.gmc-uk.org/-/media/documents/analysis-of-cases-resulting-indoctors-being-suspended-or-erased-from-the-medical-register-63534317. pdf)
36 Gilbert P. Evolution, social roles, and the differences in shame and guilt Soc Res 2003; 70(4): 1205-30.

37 Tangney J. Moral affect: the good, the bad and the ugly. J Pers Soc Psychol 1991; 61(4): 598-607.

38 Sedgwick E, Frank A. Shame and Its Sisters: A Silvan Tomkins Reader. Duke University Press, 1996.

39 Lindström UH, Hamberg K, Johansson EE. Medical students' experiences of shame in professional enculturation. Med Educ 2011; 45(10): 1016-24.

40 Schneider C. Shame, Exposure and Privacy. Norton, 1992. 